\title{
Twitter as health information source: Exploring the parameters affecting dementia-related tweets
}

\begin{abstract}
Unlike other media, research on credibility of information present on social media is limited. This limitation is even worse in the case of healthcare, including dementia-related information. The purpose of this study was to identify user groups that show high bot-like behavior and profile features that contribute to high deviation from human behavior. We collected 16,691 tweets about dementia posted over a month by 8400 users. We applied inductive coding to categorize users. The BotOrNot? API was used to compute a bot score. This work provides insight into relations of different user features with a bot score. We performed analysis techniques such as Kruskal-Wallis, stepwise multiple variable regression, user tweet frequency analysis and content analysis on the data. These were further evaluated for the most frequently referenced URLs in the tweets and most active users in terms of tweet frequency. Initial results indicated that the majority of users are regular users and not bots. However, independent variables in the user profiles such as geo_data, and favourites_count were related to the final bot score. Regression analysis showed different features are strongly related. Similarly, content analysis of the tweets showed that the word features of bot profiles have an overall smaller percentage of words compared to regular profiles. Although this analysis is promising, yet it needs further enhancements. First, the observation is performed only on Twitter data as part of developing credibility assessment framework. The results should be validated through user-focused methods. Secondly, the results of different parameters are collected in isolation. A framework should be developed for assessing and diagnosing the credibility of contents posted by users related to dementia in a unified way. This framework could also evaluate the role of tweets in spreading unreliable information.
\end{abstract}

\section{KEYWORDS}

Twitter, Credibility, Bots, Dementia, Alzheimer's

\section{Introduction}

Existing models on credibility assessment of web-based information agree that the message's source has a strong overall impact on its credibility [1][2][3]. In the presence of multiple data generation tools and social media platforms, a large volume of biased data exists. One characteristic of social media use is fast information dissemination without any evaluation of its trustworthiness. Social media consists of users from all walks of life, from expert to novice. This research is related to healthcare (dementia); an area in which every user perceives and acts upon information differently. The wrong therapies can create undesirable results. It is therefore important to investigate the credibility of information available on social media.

\section{Related Work}

Social media has become an important healthcare information source which spreads quickly as compared to traditional media. [4] assessed the use of social media among Saudi patients. The survey indicated that $85 \%$ of patients used social media for obtaining healthcare information, including $78.3 \%$ on WhatsApp, $63.4 \%$ on YouTube, and $12.3 \%$ on Facebook. $72 \%$ of users searched by themselves; $52 \%$ with family. $51 \%$ believed information on social media is reliable; $84 \%$ believed it is valuable.

Research has been conducted on Twitter usage for different diseases, but a gap remains for dementia. [5] evaluated the trends on online user activities related to 379 different diseases. Autism, diabetes, dementia, and PTSD were in the top communities by total tweets or users. This study indicates a frequent usage of Twitter for disseminating dementia-related information. Unfortunately, however, there are fewer studies for assessing the credibility of this information. Similarly, [6] considered Twitter in the spread of information 
related to dementia, information sources, and the themes of discussion about dementia. They collected 9200 tweets within 24 hours using dementia-related keywords. Based on a random sample of $10 \%$, most tweets contained hyperlinks to other websites containing health information. Also, most discussed the latest research related to prediction and assessment of dementia. The credibility of the tweets depended on the credibility of the hyperlinks.

[7] explored a Facebook page used for requesting and offering advice about dementia, associated risk factors, and prevention. It focused on understanding the nature of communication between users and health organizations. The data was collected from a Q\&A discussion on a television program about Alzheimer's. They analyzed original posts and responses. The original posts were about collecting information and typically involved posters questioning individuals' risk of dementia and their family history. Responses were usually about prevention. Only generic professional advice was present.

Studies on dementia-related social media are rare compared to other diseases such as cancer, diabetes and autism. Research discussed above indicates that dementia is a popular topic on Twitter. However, very little work has been done on it compared to other diseases.

\subsection{Social Bots in Social Media}

Many users produce and consume data on social media, and the dissemination of information on social media is a natural extension [8]. This presence tempts malicious users, also called bots, to use these platforms to betray discussion [8]-[10]. Bots are social media accounts controlled through software; defined by [11] as 'computer algorithms that automatically produce content and interact with humans on social media, thereby trying to emulate and possibly alter their behavior'. Bots cause people to lose trust in social media because they push stories to achieve certain objectives. Bots also cause deflection in research results and lead to false conclusions. Therefore, it is vital to detect the presence of bots with a high degree of accuracy. One popular tool used for Twitter bot detection is BotOrNot? This tool assigns a bot score to a profile in the range from 0 to 5 , with 0 being the most trusted profile and 5 being the most bot-like profile.

Different digital misinformation tactics have resulted in the loss of trust on social media platforms. Many studies have discussed the spread of misinformation on social media [12][13][14]. All indicate that online social contents are digitally manipulated by automated accounts, also called 'sybil accounts' or 'social bots'.

Bots are used to disseminate misleading, malicious, and negative information. One example is the 2010 infiltration of Indonesia's disaster management authority account and the spread of false information. Another example is the usage of bots in elections for maliciously increasing political support. This happened in the 2010 US elections and these candidates were hugely criticized by the public for spreading fake news through tweets [15]. This happened also in the 2016 US elections [16] where many new detection algorithms discovered a large presence of so-called legitimate social media accounts are actually bots that generate about $1 / 5$ of the conversations [16]. For election campaigns, bots are dangerous because they create a false sense of popularity online.

Social bots are widely used to automate news spreading, political campaigns and health information spreading. These bots generate tweets and retweets at the same rate as human-generated ones. Social bots could be employed also to promote products or behavior by those with clear financial gains as in the case of diet plans, tobacco and ideological beliefs for or against health decisions [17].

Alzheimer's is one of the diseases widely discussed on Twitter. Patients, caregivers, scholars and doctors use the platform to discuss their thoughts, ideas and literature on Twitter. However, not all are legitimate users. Detailed and comprehensive analysis indicates that these studies are based on the following fewer parameters in the models/frameworks and algorithms. While some studies are based on parametric evaluation of Twitter features, the behavioral elements are missing in the analysis. Since healthcare, particularly dementia, is a complex domain, it needs a fine-grained evaluation of data from multiple perspectives.

The evidence presented in this section demonstrated the need for our research questions: 1) Who are the participants in dementia-related tweets? 2) What is the likelihood that participants are bots? 3) What features contribute most to demonstrating bot-like behavior? 
This exploratory study sought to develop a codebook for users who disseminate tweets about dementia. An initial evaluation is provided on the role of social bots in the context of dementia topics on Twitter. This understanding can lead to the design and development of social bot detection and mitigation strategies.

\section{Method}

\subsection{Twitter Data Collection}

We collected the tweets with the standard (free) Twitter API and used Python 3.0. We searched tweets posted from 25 December 2017 to 6 February 2018. The query terms included the keywords 'dementia OR Alzheimer OR Alz OR Alzheimers \#dementia OR \#Alzheimer OR \#Alz OR \#Alzheimers'. Only original tweets were used; all retweets were discarded. Also, we only included tweets in English. The total number of collected tweets is $\mathrm{N}=16691$ and the unique sources $(\mathrm{N}=8400)$ that created these tweets were stored in separate files.

\subsection{Benchmark Selection for Bot Detection on Twitter}

One of the most widely used techniques in Twitter bot detection comes from Indiana University Network Science Institute (IUNI) and the Center for Complex Networks and Systems Research (CNetS) called Bot or Not? ${ }^{1}$. The BotOrNot API computed the sources' bot scores. The proposed technique used Random Forest as the machine learning classifier which learns from training data and extracts around 1,200 of the features available in metadata and content. Features are mainly grouped into six feature categories: network, user, friends, temporal, sentiment, and content. Network features are built using features such as networks based on retweets, number of hashtags and their location in tweets, other statistical features such as degree distribution, clustering coefficient, and centrality measures. User features are based on data from the account such as language, geographic location and account creation date. Friends features also use direct features such as the number of followers and posts, and indirectly computed features such as median and entropy of distribution. Temporal features are based on the behavior of bot roles on social media. Contents features are based on different cues derived from language used in the contents, especially part-of-speech tagging. Sentiment features are built using general and Twitter-specific sentiment analysis algorithms, including happiness, arousal-dominance-valence, and emoticon scores.

This tool was utilized in [16] which investigated the impact of social media bots on the 2016 US presidential election. By using the proposed detection algorithm, it is found that a very large portion (approximately onefifth) of the sources may not be human and could generate massive contents. [18] evaluated BotOrNot? in the context of vaccination. They collected a random set of tweets by using keyword strings "vax" or "vacc". The tweets are further tagged by these words using a machine learning classifier. The credibility of these tweets are evaluated using BotOrNot?, and it failed to correctly predict all bot accounts for all cases [19].

The BotOrNot? API is not only used as a benchmark in topics related to politics but also in healthcare. This makes it ideal to be used in the current study.

\section{Categorization Users' Relationship to Dementia}

Categorization of Twitter users is an important step in order to differentiate users based on their relevant groups. User profiles are the only source of information that can be used and can be validated from users for demographics. Thus, we analyzed user profiles for better user classification. Various schemes have incorporated this technique for Twitter users that discuss different types of health information [20] [21] [22].

\subsection{Inductive Coding}

Classification is required to identify the different types of accounts on Twitter. While there are many techniques for data classification, the complexity of Twitter accounts led us to inductive coding [23]. Inductive coding can be defined as a process of qualitative analysis of raw data into categories based on

${ }^{1}$ https://botometer.iuni.iu.edu/ 
inference and interpretation using the inductive reasoning of manual observation, examination and constant comparison of the researcher. The primary objective of inductive coding is to find the significant and frequent classes that are inherent in the raw data without imposing the restrictions of structured data [23]. The basic purpose of the inductive approach is to condense raw data into a summary format. Inductive coding is used to (a) find the relation between research objectives and results derived from raw data (b) understand the working of underlying processes and develop a framework that can interpret the raw data [23]. While there are many types of inductive coding, one is summative analysis which is based first on counting words and later on analysis by meaning and themes to identify word usage.

We follow the process of inductive coding of user profiles as described in [23]: 1) fetching and preparing the raw data with the user profile, 2) analytically reading the profile contents to develop a deep understanding of themes and patterns covered in the text and 3) defining themes or categories based on the understanding.

\subsubsection{Preparing Raw Data}

As an initial step, we wrote a Python script that searches professional, non-professional profiles and entities (organizations) based on keywords defined in the query. These words/phrases are set based on initial observations. For example, account descriptions that contained keywords about areas of expertise such as elderly healthcare, or professional titles (e.g. neurologist, therapist) were categorized as professionals. In the same way, phrases/words were set to define organizations (entities). The rest of the users, or if the description was left empty, were classified as individuals. The list of keywords for both types of users are shown in Table 1. Using all collected users' profiles $(\mathrm{N}=8400)$, broad categories were defined to form an initial codebook. The codebook was then refined, and more subcategories were specified. The final codebook comprised all possible categories of users.

\subsubsection{Content Review}

The profiles gathered through search queries (Table 1) were further evaluated. This evaluation required multiple readings of the raw data, also called vivo coding [23]. Different text segments among the text are manually marked and copied in emerging categories. However, specialized qualitative analysis can be used to speed up the coding process when there are large amounts of text. We derived more low-level categories from organizations (entities) by multiple readings of the entities' profiles (Table 2). A Python script was modified to set more segregation keywords to have five more categories: care providers, books, applications, promoters and media. Anything else was categorized as individual (other/non-professional). We created eight main categories in total. For each category, we created two files: one for users and one for their tweets (Table $3)$.

The possibility that automated categorization may result in outliers or incorrectly categorized accounts and to continue revision and refinement of the categories into more subcategories required us to have another annotator to review all the entries manually to ensure that these instances are restricted to an acceptable minimum in order to ensure reliable final data. The annotator was provided the codebook (Table 3 ) as a guide for user categorization.

\section{Table 1: High level search keywords}

\begin{tabular}{ll}
\hline Professional & 'dementia specialist', 'dementia researcher', 'special interest in dementia', 'dementia \\
keywords & consultant', 'Dementia's disease researcher', 'at Demential's Research', 'research in \\
& Dementia', 'Geriatrician', 'at Alzheimer's Research', 'Alzheimer Researcher', \\
& 'Alzheimer's disease researcher', 'Neuropsychologist', 'Gerontologist', 'Psychologist', \\
& "deep into Alzheimer's disease',' interest in ageing ','interest in neurodegenerative', \\
& 'Cognitive health specialist', 'Medical doctor', 'Occupational Therapist',' \#researcher', \\
psychologist', & 'Senior \\
& 'Clinical \\
& $\begin{array}{l}\text { Lecturer','Neurologist','Neuroscientist','Physician',''Biomedical scientist', 'Professor in',' } \\
\text { Psychiatrist ',' pathologist ',' Rehabilitation Consultant ',' Medical Teacher ' }\end{array}$ \\
Organization & 'The Alzheimer Society', 'Alzheimer's Association', 'Alzheimer's Disease International \\
keywords & (ADI)', 'The International Psychogeriatric Association (IPA)', 'ian Association', 'The \\
& official', 'Our mission:', 'Dementia Helpline', 'dementia organization', 'our vision',' we \\
\hline
\end{tabular}


','call us',' Tel ','join us', 'like us on', 'follow us on', '\#Helpline', 'Official Twitter page', 'Official account', 'Non-profit organization', 'mission is', 'A premier provider', 'institution', 'provides ',' aims to ', 'Dementia Forum X', 'charity', 'is a forum',' Our ','Founded in', 'consulting firm',' is a ','Institute of ','Official Twitter account' ,'a growing community', 'Aging Company', ' is the foundation ',' placement company ','Email us at', 'center for '

\section{Table 2: Lower level refined keywords}
Care providers
'Home Care Assistance', 'home caregiving services', 'home care', 'health services', 'Leading non-profit', 'homecare services',' the best care', 'state-of-the-art Memory Care', 'Inc.', '24/7'
Apps $\quad$ 'is a free app', 'platform',' Apps '
Books
'Top Books on', 'best-selling books', 'bestselling books', 'bookstore', 'Book Deals', 'Follow us for new books', 'Kindle Books'
Promoters 'your campaign promoted', 'Get Promotion For Your'
Media
'Sign up to our', 'breaking news', 'is an online magazine', 'Follow us for news', 'Follow us for healthcare news', 'Journal of ','The Journal of', 'Latest medical news', 'Daily, peer reviewed medical news',' relevant medical news ', 'medical news from',' free CMEs, medical news', 'Track the latest ','news site for ','the latest medication news', 'fully open access journal', 'Sign up for health tweets'

\section{Table 3: Categories with Description}

\begin{tabular}{lll}
\hline & \multicolumn{2}{c}{ User Categorization Code Book } \\
\hline Main category & $\begin{array}{c}\text { Sub-Category } \\
\text { and Code }\end{array}$ & \multicolumn{1}{c}{ Description of Qualifying User Account } \\
\hline $\begin{array}{l}\text { Individuals- } \\
\text { Professionals }\end{array}$ & $\begin{array}{l}\text { Medical } \\
\text { Professiona } \\
\text { ls }\end{array}$ & $\begin{array}{l}\text { Individual users who include professional medical titles (as } \\
\text { recognized by health practitioner registrations boards) in their } \\
\text { Bio-descriptions e.g. doctor, registered nurse, nurse, physician, } \\
\text { neurologist etc. or academic titles (professor of clinical } \\
\text { neuropsychology, professor of integrative medicine etc.). }\end{array}$ \\
(IP-MP)
\end{tabular}

Examples of terms and/or phrases indicate medical titles you may find in their descriptions include, but are not limited to. [Neurologist] [Neuro-surgeon] [Neuro-psychologist] [Organizational Psychologist] [Social geriatrician] [Occupational Therapist] [Rehabilitation Consultant] [Mental health specialist] [Nursing home doctor] [Biomedical Scientist] [Speech pathologist] or combinations of the above.

\begin{tabular}{lll}
\hline & $\begin{array}{l}\text { Health } \\
\text { Activist }\end{array}$ & $\begin{array}{l}\text { Individual users who are dementia/Alzheimer's/mental heal } \\
\text { advocates or who are involved in active campaigning with the } \\
\text { purpose of bringing about human or social change in the field } \\
\text { of healthcare. }\end{array}$ \\
Other & $\begin{array}{l}\text { (IO-HA) } \\
\text { Caregiver }\end{array}$ & $\begin{array}{l}\text { Formal /informal carers who provide care to person with } \\
\text { dementia. (regardless if he/she has medical qualification or }\end{array}$
\end{tabular}


occupation relating to the field of dementia / Alzheimer's disease).

Artist (IO- Individual users notable for their fame in the field of music, A) photography, art, song.

Individual users who specialize in marketing to promote their Marketer (IO-M)

Author (IOAU)

Others (IOLP)

\begin{tabular}{ll}
\hline Entities: & General \\
Organizations & Organizatio
\end{tabular}
ns

HomeCareP rovider $(\mathrm{E}-$ OCP) own products, books or equipment or work on the behalf of a company/organization to promote products, books, equipment etc.

Individual users who are expert writers and publish written material in works such as books, newspapers, magazines, etc.

Individual users who do not belong in the above categories.
Organizations include government/public organizations, private organizations, non-profit organizations, interest groups, or charities that provide emotional support, activities, research, arrange seminars and develop communities.

Entities including profit or non-profit home care providers or providers of services specifically for people with dementia and/or their caregivers and families.
It may include agency or web directory help to find senior care providers

Bio-descriptors may include phrases such as home care assistance, care-giver services, carer-services, nursing services, caregiver training, private duty home care, mobility assistance, memory care, rehabilitation, health and wellbeing services, music therapy etc.

$\begin{array}{ll}\text { Entities: } & \text { Promoters } \\ \text { Promoters } & \text { (E-P) }\end{array}$

Promoters include technology and product development companies related directly to healthcare (e,g. devices, pharmaceuticals, biotechnologies). They also include marketing companies providing services or products not related directly to healthcare (e.g. law services, food, furniture).

\begin{tabular}{lll}
\hline $\begin{array}{l}\text { Entities: } \\
\text { Media }\end{array}$ & $\begin{array}{l}\text { Media includes electronic media such as news channels (BBC, } \\
\text { CNN), print media such as newspapers (NewYork Times), } \\
\text { Research media (Journal articles, research papers etc), website } \\
\text { or social media profile (Facebook, Instagram) to provide tips } \\
\text { and information related to health. }\end{array}$ \\
\hline Books and & $\begin{array}{l}\text { Books (E- } \\
\text { Applications }\end{array}$ & $\begin{array}{l}\text { An account for book publishers, tweeting about collection of } \\
\text { books or is linked to a specific published book. }\end{array}$ \\
& $\begin{array}{l}\text { Dementia- } \\
\text { App (E- }\end{array}$ & $\begin{array}{l}\text { An account for a software program/app/tool /game/system that } \\
\text { is specifically designed to serve people with dementia or } \\
\text { AD) }\end{array}$ \\
& Alzheimer disease, their families and caregivers.
\end{tabular}


Health-App An account for a software program/application/tool that is

(E-AH) designed to serve general health and well-being

Empty and

Unknown includes places or events (e.g. conferences)

Unknown

Empty category referred to profiles without descriptions

\subsubsection{Data Sample Validation through Inter-annotator Agreement}

The data is sampled for 2000 users from the entire dataset of 8400 users. Data sample validation was done by another annotator who is a researcher with established skills in information science. The codebook was provided to the annotator to assign a category for each user in the sample. The annotator's category result is intersected with our category for common identifiers using an R Studio script. Furthermore, the data is cleaned to remove extra tags, spelling errors and unwanted characters that can produce noise in the results. On the resultant data, Cohen's Kappa [24] was applied to find the level of agreement between two different annotators in assigning categories to individual profiles. The results indicate $76 \%$ agreement between the annotators, which is a substantial level of agreement. This percentage of agreement is due to a large number of categories and agrees with the percentage provided for Twitter data categorization [21][22].

\section{Results}

Eight different categories were identified, with the highest number of users in the Individual category and lowest number in the Applications and Books category (Table 4; Figure 1). These results also indicate the clear presence of organizations and care services providers such as home-care services.

Table 4: Different Categories of Profiles through Inductive Coding

\begin{tabular}{ll}
\hline Category & Total Users \\
\hline Individuals & 3899 \\
E-Organizations & 1223 \\
E-Care Providers & 831 \\
Professionals & 784 \\
Empty and Unknown & 593 \\
E-Promoters & 509 \\
E-Media & 474 \\
E-App and E-Book & 76 \\
\hline
\end{tabular}




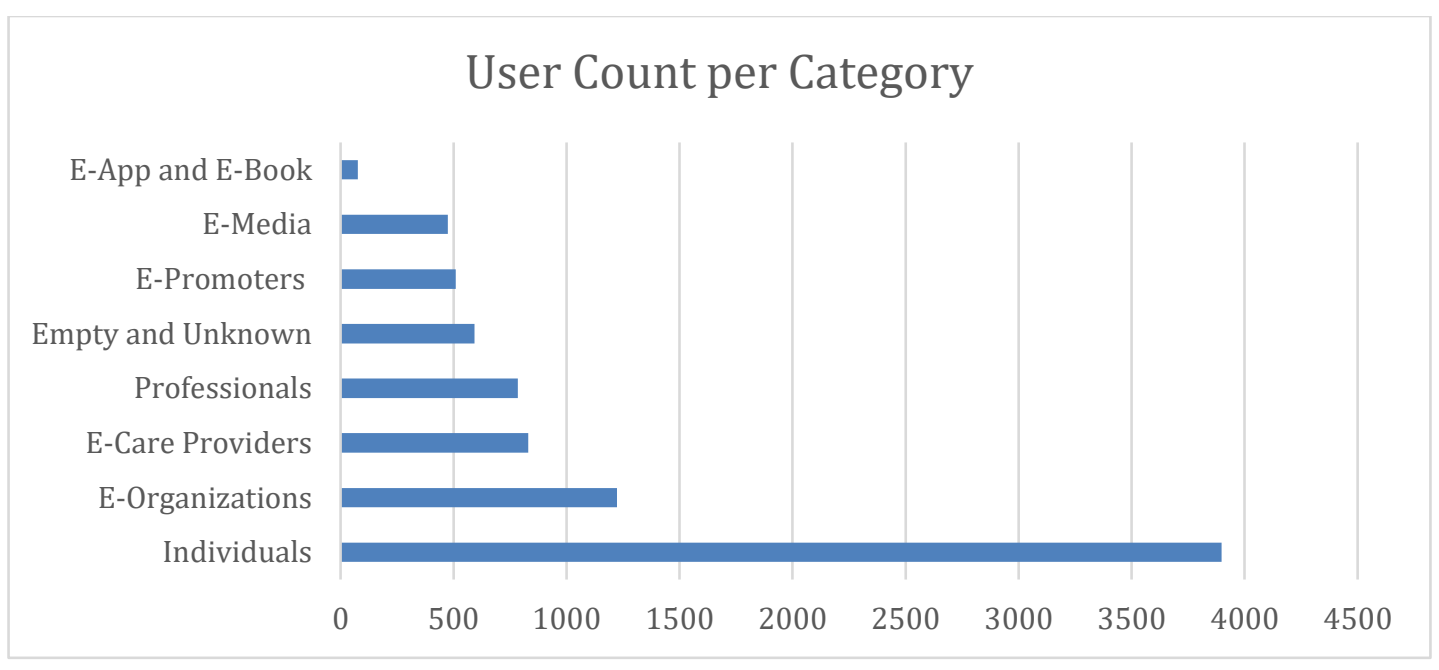

Figure 1: User Count in Different Categories

\subsection{BotOrNot? API Score Analysis}

In addition to inductive coding, it was also important to apply statistical tests on the users' categories. These tests not only helped in differentiating human-like and bot-like users but also provide the population of users that show bot-like behavior in each category.

\subsubsection{Kruskal-Wallis Test}

Kruskal-Wallis (KW) is a nonparametric test used to investigate whether the mean of an independent variable (bot score) varies among different categories. KW helped us decide whether the population distributions are identical without assuming they follow the normal distribution. The p-value of 0.05 was used for the statistical significance level. The test result is chi-squared $=2177.125, \mathrm{df}=7, \mathrm{p}$-value $<0.0005$. The $\mathrm{p}$-value is nearly zero; hence, the hypothesis that all categories follow identical distributions is rejected and bot scores are not identical in different categories of population.

\subsubsection{Bot Score based on Categories}

The BotOrNot? API is applied to compute the score of all users in different categories. It failed to generate scores for 7 accounts because these accounts are either suspended or deleted. The bot-score ranges from 0-5, where zero refers to most human-like behavior and 5 refers to bot-like behavior. Different studies have interpreted the bot-score range in different ways. For example, one study categorized bot score in three categories where bot-score 0-1 represent human-like behavior, 2-4 represent ambiguous behavior and 4-5 show bot-like behavior [18]. Another study distributed the probability mass of bot score ranging 0-1 [16]. It is found that most of the bot mass is concentrated in the range 0.2 to 0.5 . Also, the account having bot score greater than 0.5 exhibits high bot-like characteristics. Thus, it can be assumed that a score in the range 2-3 signals the uncertainty of API about the Twitter profile. The score ranging 3.1-5 is considered as a bot due to its bias towards bot users rather than normal users.

Previous studies considered 3.1-5 as the bot range [25]. BotOrNot? provides two different accumulative scores: the English score and the Universal score. The English score uses all six categories of features, whereas the Universal score does not include the English-specific sentiment and content features. For all main categories identified through inductive coding, the average English score is provided in Table 5. 
Table 5: Categories with bot score

\begin{tabular}{lcccc}
\hline \multicolumn{1}{c}{ Category } & $\begin{array}{c}\text { Total } \\
\text { Records }\end{array}$ & $\begin{array}{c}\text { Overall Bot } \\
\text { Score Mean }\end{array}$ & $\begin{array}{c}\text { \% (3-5) Bot } \\
\text { Score }\end{array}$ & $\begin{array}{c}\text { (3-5) Bot } \\
\text { Score Mean }\end{array}$ \\
\hline All & 8400 & 1.32 & 13.85 & 3.73 \\
Individuals & 3899 & 0.909 & 7.51 & 3.71 \\
E-Organizations & 1223 & 1.620 & 13.39 & 3.65 \\
E-Care Providers & 831 & 2.481 & 39.83 & 3.73 \\
E-Media & 474 & 1.63 & 15.3 & 3.75 \\
Professionals & 784 & 1.069 & 9.05 & 3.83 \\
E-Promoters & 520 & 1.953 & 25.76 & 3.75 \\
Empty and Unknown & 593 & 1.176 & 10.79 & 3.70 \\
E-App and E-Book & 76 & 2.35 & 38.15 & 4.00 \\
\hline
\end{tabular}
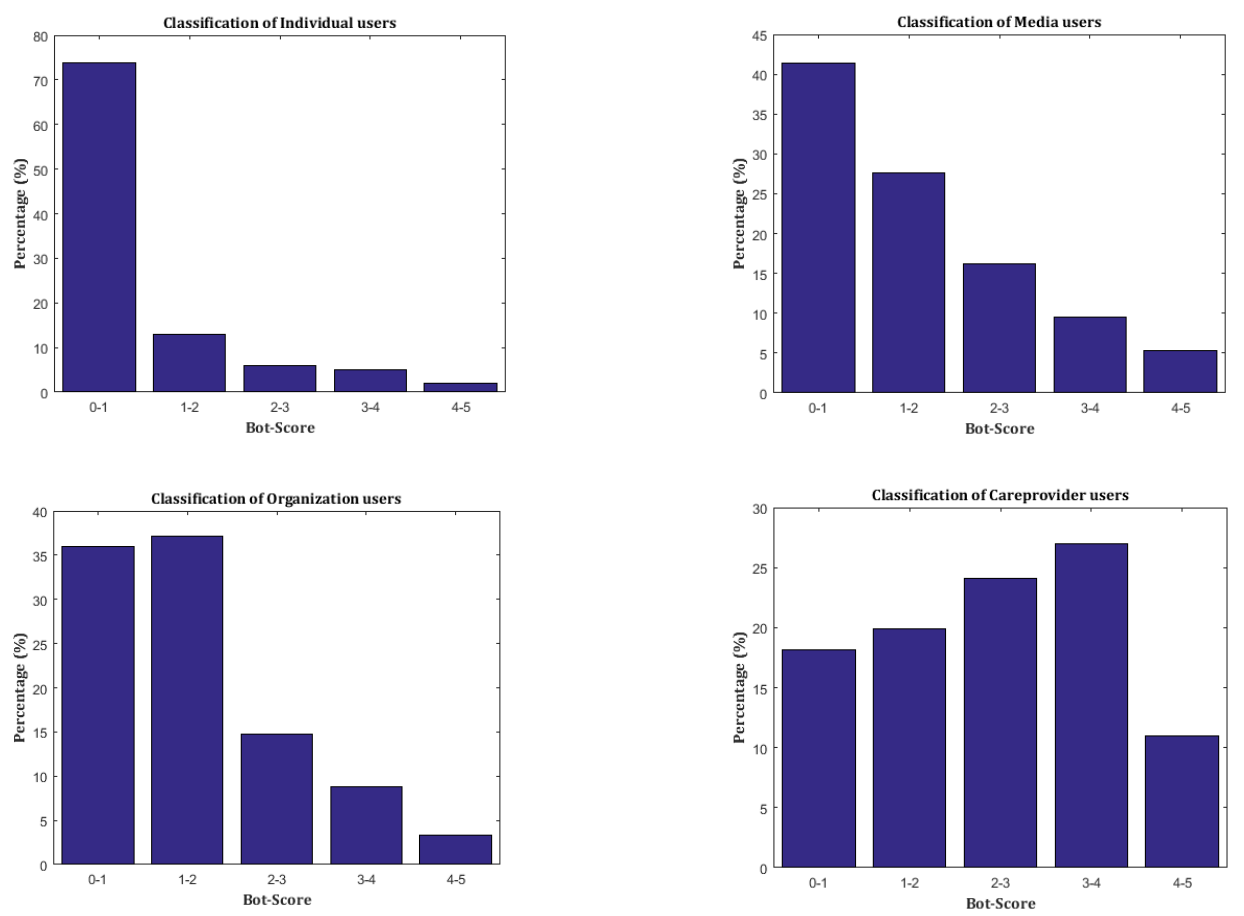

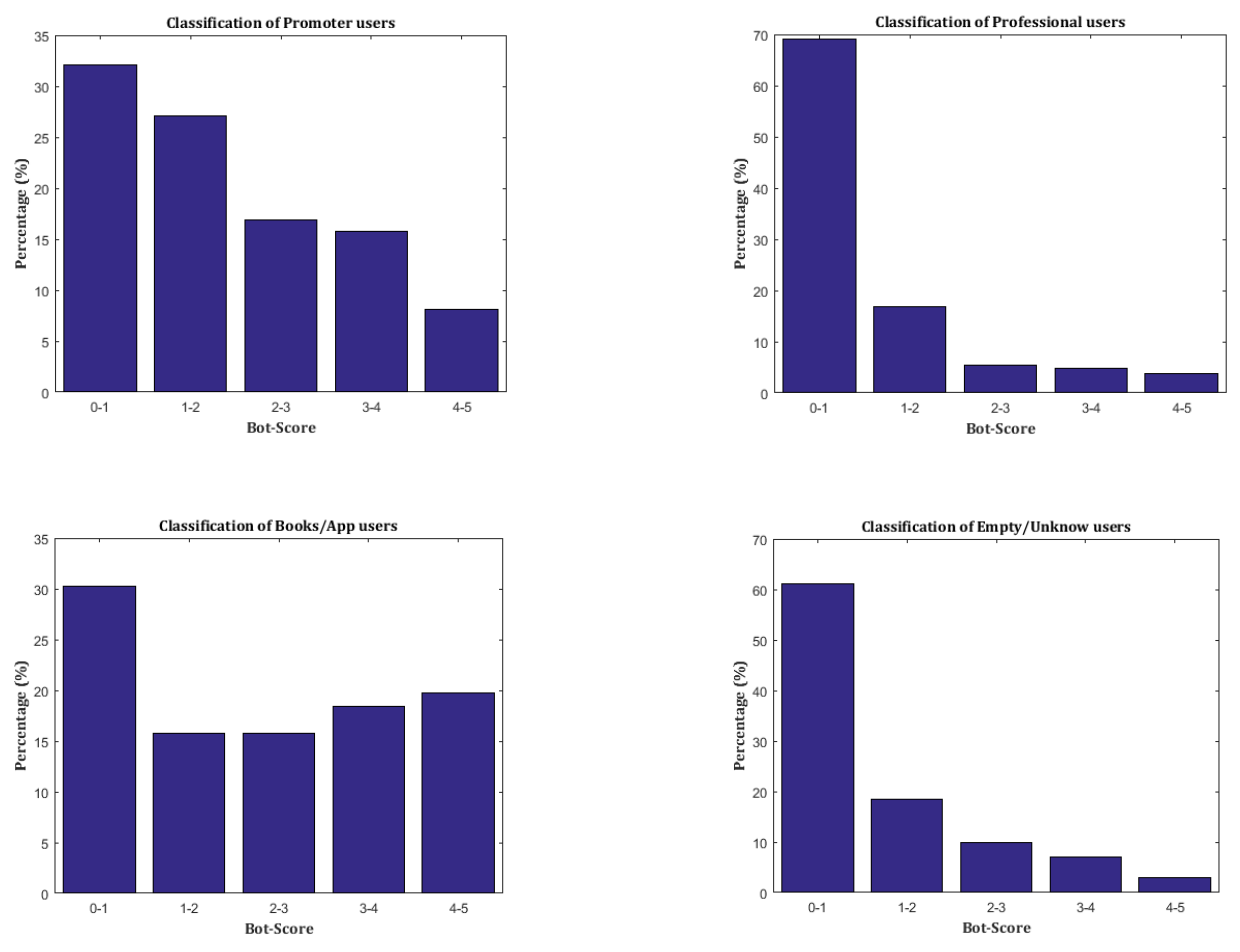

Figure 2: Score-wise Distribution in Each Category

The carers and books/apps categories show a comparatively high average overall bot-score. The category of books/apps show the highest average bot-score in the range of 3-5.

Bot Score-wise profile distribution in different categories is shown in Figure 2 with the results of each category and accumulative scores. These results demonstrate that all categories except carers and books/apps show similar patterns of bot scores in comparison with user percentages. The maximum value of the bot score in a certain category is negatively related to the percentage of users. Similarly, the minimum value of a bot score in a certain category follows an exponential drop with the number of users. A similar pattern for bots is observed with score ranging 3-5 in profiles related to organizations, media, promoters, and empty/unknown categories. A low percentage of a high bot score is observed for individuals $(7.51 \%)$ and professionals $(9.05 \%)$.

All bot scores categories are based on language (English). These results also indicate the average bot score to be 1.32 which reflects that most of the accounts are legitimate accounts. These results are further complemented by other research [19], which shows that the computation of credibility using BotOrNot? is not completely correct. This led us to explore the data for identifying other relationships.

\subsection{Frequency of URLs in Tweets}

Twitter's limitation of 280 characters in a tweet sometimes makes it helpful for a user to provide a URL with more detail. Thus, the frequency of any URL inside the tweet could be a good indicator of tweet or profile credibility. A survey about user perception of information credibility on social media [26] showed that users' perception of credibility was poor; they perceived tweets as more credible if a user image, username, URLs and location are provided. [27] considered multiple features of tweets such as retweets, references to external information sources and contents; tweets with URLs are considered more credible compared to tweets without them. In order to find the frequency of a particular URL type used by users within tweets, we extracted all URLs embedded in the tweet dataset $(\mathrm{N}=16691)$. These URLs were cleaned, and only the domain name was shortlisted for analysis. Also, if the same user included the same URL more than once, it was counted as one. The most common URLs along with their frequency are shown in Table 6. 
An initial overview of these domains shows that people refer to social media platforms such as YouTube, Instagram and Facebook and news websites such as The New York Times and the BBC compared to more reliable and authentic information sources. People also showed interest in sharing e-commerce websites such as Amazon, and health information websites such as www.medicalnewstoday.com and dailycaring.com.

Also, Table 7 provides initial analysis on the usage of different websites in different tweets along with the bot score in the profiles. Popular social networks, online communities and news websites are found in the complete range of bot scores. However, dementia-specific information websites are found in a larger number of profiles with a high bot score (3.1-5).

Table 6: URL Frequency in Tweets

\begin{tabular}{|c|c|c|c|}
\hline No & URL & $\begin{array}{c}\text { Frequenc } \\
y\end{array}$ & Domain type \\
\hline 1 & www.youtube.com & 386 & Arts and Entertainment \\
\hline 2 & myalzheimersstory.com & 372 & Health/Geriatric and Aging Care \\
\hline 3 & www.amazon.com & 369 & E-commerce and Shopping \\
\hline 4 & www.instagram.com & 241 & Social Networks and Online Communities \\
\hline 5 & www.facebook.com & 210 & Social Networks and Online Communities \\
\hline 6 & www.medicalnewstoday.com & 176 & Healthline Media (UK) \\
\hline 7 & www.nytimes.com & 175 & News and Media (UK) \\
\hline 8 & www.bioportfolio.com & 171 & News and Media (US) \\
\hline 9 & www.bbc.co.uk & 158 & Health/News and Media \\
\hline 10 & www.linkedin.com & 128 & Social Networks and Online Communities \\
\hline
\end{tabular}

Table 7: Top URL with tweet frequency in based on user bot score

\begin{tabular}{|c|c|c|c|}
\hline Bot Score & URL & Frequency & Domain type \\
\hline \multirow{6}{*}{$0-2.9$} & $\begin{array}{l}\text { myalzheimersstory.com } \\
\text { www.amazon.com }\end{array}$ & $\begin{array}{l}371 \\
270\end{array}$ & $\begin{array}{l}\text { Health/Geriatric and Aging Care } \\
\text { E-commerce and Shopping }\end{array}$ \\
\hline & www.youtube.com & 254 & Arts and Entertainment \\
\hline & www.instagram.com & 205 & $\begin{array}{l}\text { Social Networks \& Online } \\
\text { Communities }\end{array}$ \\
\hline & www.bioportfolio.com & 171 & News and Media \\
\hline & www.facebook.com & 155 & $\begin{array}{l}\text { Social Networks \& Online } \\
\text { Communities }\end{array}$ \\
\hline & www.bbc.co.uk & 136 & News and Media \\
\hline
\end{tabular}




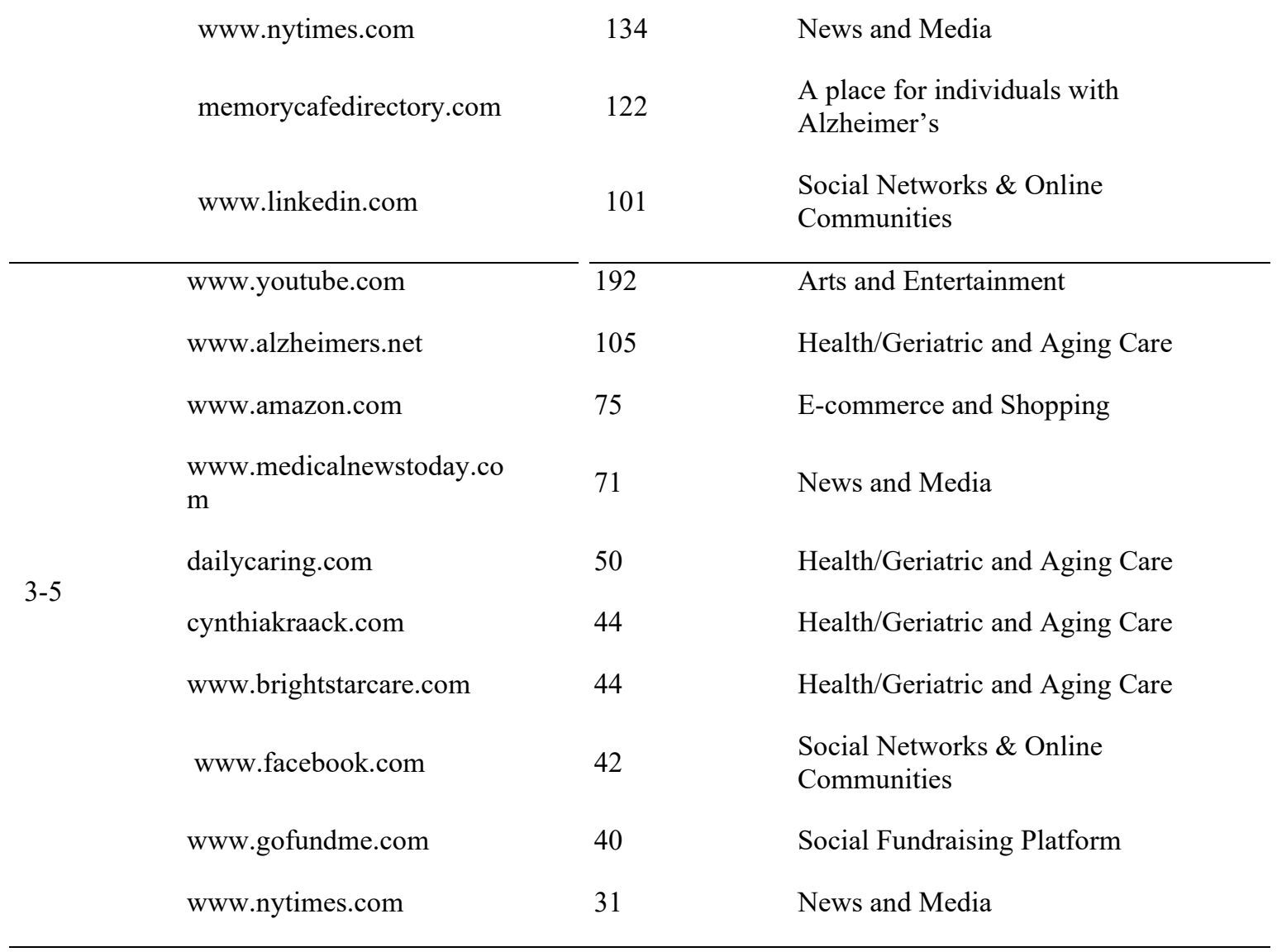

\subsection{Tweet Frequency of Top Users}

Another important parameter is the frequency of influential user tweets during a month and tools used to post their tweets. For this, we separated out the top five users from our dataset and analyzed their tweets' frequency per week as shown in Figure 4. As shown in Table 8, 5 of the 10 top users are carers. Also, different automated social media management tools such as SocialOomph, Hootsuite, Buffer, and dlvr.it generate a high volume of tweets that contain words such as dementia/alz/Alzheimer. Most top frequency users have low bot scores. A brief analysis of bot scores and software tools which post tweets indicate no direct relationship. Most high frequency postings are due to tools that generate tweets automatically after a defined interval. Thus, it further strengthens the need to explore the feature(s) that are linked to establish the users' credibility and their tweets. Also, these tools post the most tweets. These facts strengthen the need for the development of a new credibility assessment model. 


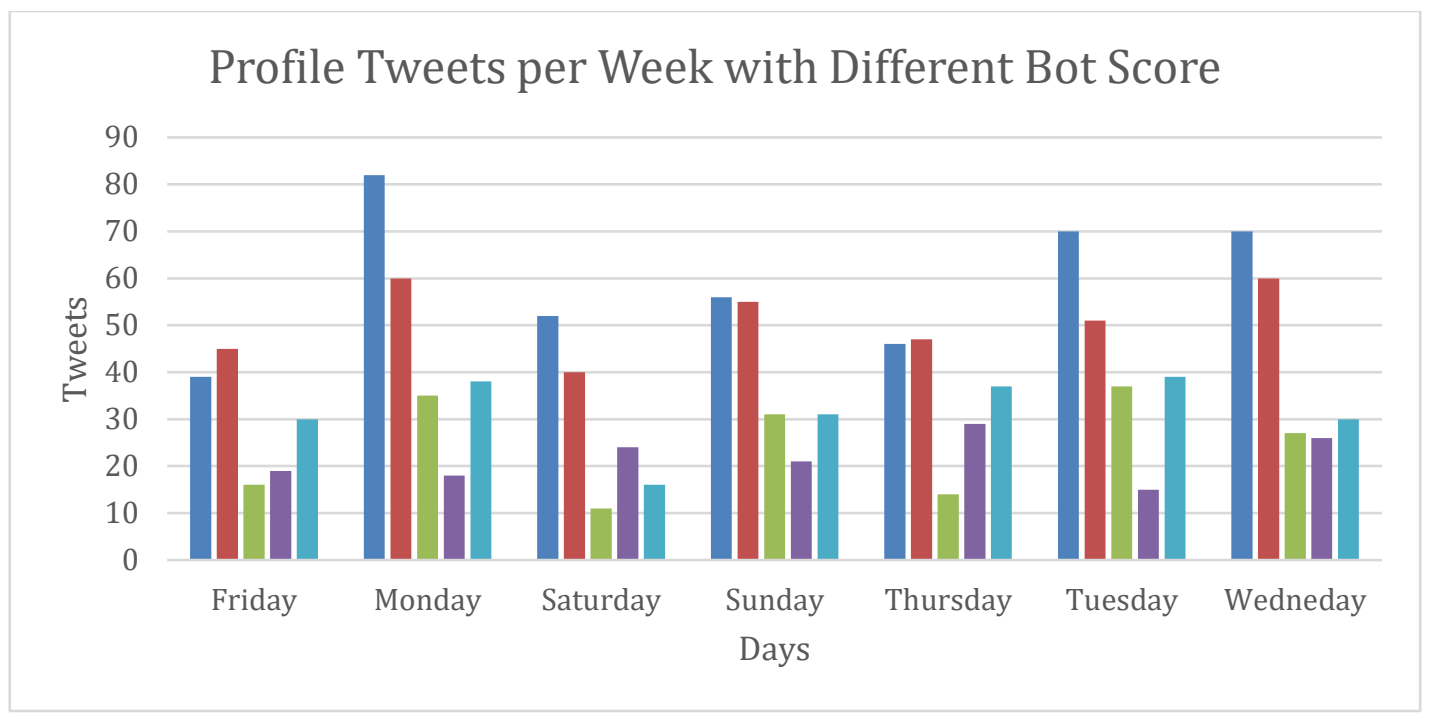

Figure 3: Frequency of Tweets per User

Table 8: Frequency of Tweets for top 10 users along with their Social Bots Score

\begin{tabular}{|c|c|c|c|c|c|c|}
\hline User & $\begin{array}{l}\text { Tweets } \\
\text { /month }\end{array}$ & Tool & $\begin{array}{c}\text { Total } \\
\text { Tweets }\end{array}$ & Generated By & Category & Bot-Score \\
\hline 1 & 415 & $\begin{array}{l}\text { Facebook } \\
\text { TweetDeck } \\
\text { SocialOomph }\end{array}$ & $\begin{array}{l}44 \\
1 \\
370\end{array}$ & $\begin{array}{l}\text { Software } \\
\text { tools }\end{array}$ & $\begin{array}{l}\text { I- } \\
\text { Individual } \\
\text { (IO-HA) }\end{array}$ & 1.4 \\
\hline 2 & 358 & $\begin{array}{l}\text { Twitter Web Client } \\
\text { TweetDeck }\end{array}$ & $\begin{array}{l}2 \\
356\end{array}$ & $\begin{array}{l}\text { Software } \\
\text { tools/users }\end{array}$ & $\begin{array}{l}\text { E- } \\
\text { Organizati } \\
\text { on }\end{array}$ & 2 \\
\hline 3 & 171 & dlvr.it & 171 & $\begin{array}{l}\text { Software } \\
\text { tools }\end{array}$ & E-Media & 2.6 \\
\hline 4 & 152 & $\begin{array}{l}\text { Twitter Web Client } \\
\text { Twitter for iPhone } \\
\text { Hootsuite Inc. }\end{array}$ & $\begin{array}{l}1 \\
5 \\
146\end{array}$ & $\begin{array}{l}\text { Users/ } \\
\text { Software } \\
\text { tools }\end{array}$ & $\begin{array}{l}\text { E- } \\
\text { Organizati } \\
\text { on }\end{array}$ & 2.6 \\
\hline 5 & 147 & $\begin{array}{l}\text { Twitter Web Client } \\
\text { Facebook }\end{array}$ & $\begin{array}{l}77 \\
70\end{array}$ & $\begin{array}{l}\text { Users/ } \\
\text { Software } \\
\text { tools }\end{array}$ & $\begin{array}{l}\text { E- } \\
\text { Organizati } \\
\text { on }\end{array}$ & 0.7 \\
\hline 6 & 119 & The Social Jukebox & 119 & $\begin{array}{l}\text { Users/ } \\
\text { Software } \\
\text { tools }\end{array}$ & Individual & 4.4 \\
\hline
\end{tabular}




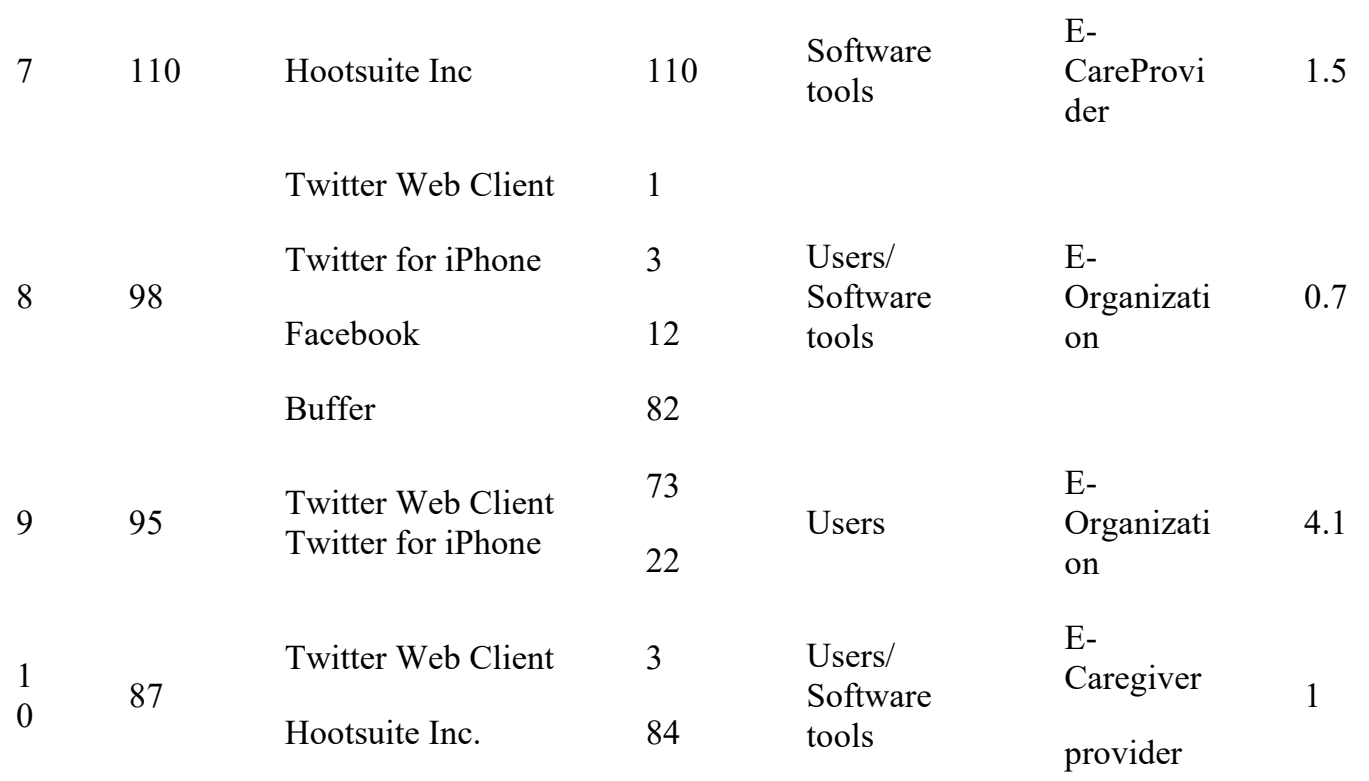

\subsection{Dependent Variable Analysis}

We checked the data for significance and dependency of dependent variable (bot score) on independent variables in users' profiles. Initially, seven publicly available features from the Twitter API were selected for evaluation since these features are publicly available and mostly apparent for Twitter's audience. Stepwise multi-regression was performed to check the impact of independent variables and then coefficients and intercepts of the regression line were computed for prediction values. These features are defined as $\mathrm{X} 1=$ verified, $\mathrm{X} 2=$ followers_count, $\mathrm{X} 3=$ friends_count, $\mathrm{X} 4=$ listed_count, $\mathrm{X} 5=$ favourites_count, $\mathrm{X} 6=$ statuses_ count, $X 7=$ geo_enabled, $Z=$ Botscore (see Table 9).

\section{Table 9: Terms and Definitions ${ }^{2}$}

\begin{tabular}{ll}
\hline Feature & Definition \\
\hline Verified & Indicates that the user has a verified account. \\
Followers_count & The number of followers this account currently has. \\
Friends_count & The number of users this account is following (AKA their "followings"). \\
listed_count & The number of public lists that this user is a member of. \\
favourites_count & $\begin{array}{l}\text { The number of Tweets this user has liked in the account's lifetime. } \\
\text { British spelling used in the field name for historical reasons. } \\
\text { statuses_count }\end{array}$ \\
geo_enabled & The number of Tweets (including retweets) issued by the user. \\
\hline
\end{tabular}

\subsubsection{Whole Data Analysis}

To investigate the impact of available independent features X1, X2, X3, X4, X5, X6, and X7 on dependent variable score $\mathrm{Z}$, we performed stepwise multiple regression analysis which does multiple regression several

\footnotetext{
${ }^{2}$ https://developer.twitter.com/en/docs/tweets/data-dictionary/overview/user-object
} 
times, each time removing the weakest correlated variable. Bot score is not necessarily affected by all independent variables. For the users dataset, four factors (X7, X5, X3, and X1) affected the result of the bot score while X2, X4 and X6 were not included. We performed stepwise multiple regression analysis for the whole dataset in terms of the $\mathrm{R}$ value. Adjusted $\mathrm{R}^{2}$ appears in Table 10 .

Table 10: Stepwise Multiple Regression Analysis for whole data ( $=8400)$

\begin{tabular}{lllll}
\hline No & Variable Entered & $\mathrm{R}$ & $\mathrm{R}$ Square & Adjusted R-Square \\
\hline 1 & $\mathrm{X} 7$ & .192 & .037 & .037 \\
2 & $\mathrm{X} 7+\mathrm{X} 5$ & .215 & .046 & .046 \\
3 & $\mathrm{X} 7+\mathrm{X} 5+\mathrm{X} 3$ & .226 & .051 & .051 \\
4 & $\mathrm{X} 7+\mathrm{X} 5+\mathrm{X} 3+\mathrm{X} 1$ & .231 & .053 & .053 \\
\hline
\end{tabular}

Table 11: ANOVA values for whole data $(\mathrm{N}=\mathbf{8 4 0 0})$

\begin{tabular}{llllll} 
The Source & Sum of Squares & df & Mean Square & F Value & Sig. \\
\hline Regression & 640.529 & 4 & 160.132 & 118.414 & .000 \\
Residual & 11340.430 & 8386 & 1.352 & & \\
\hline
\end{tabular}

Table 12: Coefficient and Constant values for regression equation

\begin{tabular}{llllll}
\hline Independent variables & $\mathrm{B}$ & Std. Error & Beta $(\beta)$ & T Value & Sig. \\
Constant & 1.563 & .0 .18 & & 85.662 & .000 \\
X7 & -.448 & .025 & -.187 & -17.602 & .000 \\
X5 & -0.00000452 & .000 & -.109 & -10.062 & .000 \\
X3 & 0.00000934 & .000 & .114 & 11.230 & .000 \\
X1 & -.281 & .062 & -.048 & -4.521 & .000 \\
\hline
\end{tabular}

The value of Adjusted $\mathrm{R}^{2}$ is .053 (Table 10) which means that four factors indicate $5.3 \%$ the variance for the bot score variable. ANOVA analysis is provided in Table 11 to find the significance level of the variables affecting prediction of $Z$. The F-value (the overall statistical significance of the model as a whole) is 0.01 indicating the statistical significance for factors $\mathrm{X} 7, \mathrm{X} 5, \mathrm{X} 3$, and $\mathrm{X} 1$ that contribute to the prediction of dependent variable $\mathrm{Z}$. Table 12 provides values for $\mathrm{B}$ constant and values of for independent variables There is a negative effect of geo_enabled, favorites count, verified variables with significance level 0.01 and positive effect of friends_count with significance of 0.01 . Thus, the regression equation can be defined as follows:

Estimated $Z=A_{1} X_{7}+A_{2} X_{5}+A_{3} X_{3}+A_{4} X_{1}+A_{5} X_{2}+B$ (1)

$\mathrm{A} 1=-.448, \mathrm{~A} 2=-0.00000452, \mathrm{~A} 3=0.00000934, \mathrm{~A} 4=-.281$ and $\mathrm{B}$ is the value of constant of regression $=$ 1.563 . 
Similarly, the stepwise multiple regression analysis for users with bot score $0-2.9$ indicate adjusted $\mathrm{R}^{2}$ value is 0.018 , which indicates the total variance for the bot score variable is $1.8 \%$ for all variables. The bot score analysis in the 3-5 range provides an adjusted $\mathrm{R}^{2}$ value of 0.019 , which indicates the total variance for the bot score variable is $1.9 \%$ for all variables. Another important finding is the negative coefficient values of $\mathrm{X} 7$ and X5 for the whole dataset, bot score 0-2.9 and 3-5 dataset. These negative values are used to adjust the regression line.

\subsection{Content Analysis}

The objective of the content analysis was to find variations in different words and Part of Speech-related features, whether they are generated from a normal profile or a bot profile. For this purpose, two equal-length datasets are extracted, one ranging from 0-1 and another ranging from 4-5. The purpose of choosing extreme scores is to differentiate between human- and bot-like behavior. Word level analysis of 900 tweets is provided in Table 13. These tweets were selected randomly from a larger dataset for a bot score in the range of $0-1$ and another for range 4-5. We used the Posit toolset for content analysis; results are provided in Table 13. Posit was first introduced in [28] and used in recent studies [29][30].

The results obtained indicate important findings. First, the number of total words (tokens) are more for bot score $0-1$ as compared to total words for bot score 4-5 for the same number of tweets. However, the number of characters in bot profiles are much higher than regular profiles. This is because bot profiles demonstrated longer words as compared to regular profiles. Second, the bot profile 4-5 has fewer unique word types (22.81\%) compared to regular profiles $(28.58 \%)$ Third, a large number of nouns are used in bot profiles $(60 \%)$ as compared to regular profiles $(49.68 \%)$. Fourth, personal/possessive pronouns show a very different percentage in both types of profiles. Overall, the word features show a smaller percentage in text data in the bot profiles compared to regular profiles with the exception of noun features, number of characters and type to token ratio. These results indicate that word analysis can help credibility assessment.

\section{Table 13: Word-level Analysis of Tweets}

\begin{tabular}{|c|c|c|c|c|c|}
\hline \multirow[b]{2}{*}{ No } & \multirow[b]{2}{*}{ Word Feature } & \multicolumn{2}{|c|}{ Bot Score (0-1) } & \multicolumn{2}{|c|}{ Bot Score (4-5) } \\
\hline & & Count & Percentage & Count & Percentage \\
\hline 1 & Total words (tokens) & 23498 & & 20397 & \\
\hline 2 & Total unique words (types) & 6716 & 28.58 & 4653 & 22.81 \\
\hline 3 & Type/Token Ratio (TTR) & 3.49881 & & 4.38362 & \\
\hline 4 & Number of sentences & 3498 & 14.88 & 3446 & 16.89 \\
\hline 5 & $\begin{array}{l}\text { Average sentence length } \\
\text { (ASL) }\end{array}$ & 6.71755 & & 5.91904 & \\
\hline 6 & Number of characters & 216889 & & 230234 & \\
\hline 7 & $\begin{array}{l}\text { Average word length } \\
\text { (AWL) }\end{array}$ & 9.2301 & & 11.2876 & \\
\hline 8 & noun_types & 4342 & 18.47 & 2782 & 13.63 \\
\hline 9 & verb_types & 1327 & 5.64 & 802 & 3.93 \\
\hline 10 & adjective_types & 764 & 3.25 & 602 & 2.95 \\
\hline 11 & adverb_types & 228 & 0.97 & 135 & 0.66 \\
\hline
\end{tabular}




\begin{tabular}{|c|c|c|c|c|c|}
\hline 12 & preposition_types & 77 & 0.327 & 55 & 0.26 \\
\hline 13 & personal_pronoun_types & 31 & & 20 & \\
\hline 14 & determiner_types & 21 & & 18 & \\
\hline 15 & possessive_pronoun_types & 16 & & 9 & \\
\hline 16 & particle_types & 9 & & 5 & \\
\hline 17 & interjection_types & 6 & & 2 & \\
\hline 18 & nouns & 11674 & 49.68 & 12238 & 60 \\
\hline 19 & verbs & 4587 & 19.52 & 3641 & 17.85 \\
\hline 20 & prepositions & 2296 & 9.77 & 1762 & 8.63 \\
\hline 21 & adjectives & 1848 & 7.86 & 1527 & 7.48 \\
\hline 22 & determiners & 1489 & 6.33 & 1223 & 6 \\
\hline 23 & adverbs & 1073 & 4.56 & 615 & 3 \\
\hline 24 & personal pronouns & 1011 & 4.30 & 481 & 2.35 \\
\hline 25 & possessive pronouns & 469 & 2 & 221 & 1.08 \\
\hline 26 & particles & 82 & & 53 & \\
\hline 27 & interjections & 12 & & 3 & \\
\hline
\end{tabular}

\subsection{Topic Modeling}

Grouping in text-based data can be discovered using an unsupervised machine-learning based algorithm called topic modeling. It is Bayesian model-based probability distribution among the words in the text. This algorithm separates most-used and least-used words. However, it is difficult to apply this approach on this dataset because the units of analysis (tweets) are so short. A common variant of the topic modeling technique is the Latent Direchlet Allocation (LDA) algorithm which is widely used with social media data and microblogging sites. There are various studies that have used Twitter for topic modeling [31] [32] [33].

However, Twitter has a 280-character limit, which makes it unsuitable for analysis for popular topic models since individual tweets do not provide reasonably strong information. We solved this problem by concatenating tweets by the same author [33][32]. We followed a similar approach by applying LDA for each category of tweets using Python. Since the quality of results depends on data preprocessing, we performed tokenization, data splitting into sentences and words. Standard preprocessing steps such as converting all text to lowercase and removing special characters were applied. Also, words that have fewer than three characters were removed. Keywords in the query (e.g. dementia, Alzheimer, disease) and stop words were removed. We specified four terms in each topic. The output of the process is returned in the form of a word cloud for better representation of each category returned by LDA (Table 14).

Words/topics around care were used frequently in most topics of all main categories. All main categories share another word within their topics: "research". However, exploring different subcategories of Individuals indicate that only the sub-category of Advocate discusses "research" (Table 15). Some categories, such as organizations and carers, can be clearly identified from the top topic extracted through LDA. However, some categories such as media do not provide indication through specific keywords such as the name of the original source (newspaper, news channel) or other information that could help identify the category. This is because 
the URLs of newspapers were cleaned from the data and only the contents of News were discussed. The intent of data cleaning was to identify the topic of discussion rather than its source.

Table 14: Topic modeling in different Categories

\begin{tabular}{|c|c|c|c|c|}
\hline Users & Topic1 & Topic2 & Topic3 & Topic4 \\
\hline $\begin{array}{c}\text { E- } \\
\text { Organization } \\
\text { s }\end{array}$ & $\begin{array}{l}\text { research people } \\
\text { help } \\
\text { support }\end{array}$ & $\begin{array}{c}\text { healthr isk } \\
\text { study } \\
\text { brain }\end{array}$ & 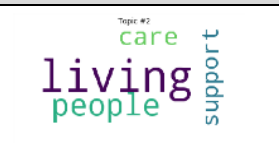 & $\begin{array}{c}\text { people new } \\
\text { care }\end{array}$ \\
\hline $\begin{array}{l}\text { E-Care } \\
\text { Providers }\end{array}$ & $\begin{array}{l}\text { researto } \\
\text { people } \\
\text { studycare }\end{array}$ & elder dy & $\begin{array}{l}\text { book } \\
\text { mus }\end{array}$ & $\begin{array}{l}\text { careephoto } \\
\text { endloneliness } \\
\text { people }\end{array}$ \\
\hline E-Media & $\begin{array}{c}\text { aepis } \\
\text { awareness } \\
\text { patients } \\
\text { mentalhealth } \\
\text { brain }\end{array}$ & $\begin{array}{c}\text { blood } \\
\text { cognitive } \\
\text { healthrisk }\end{array}$ & $\begin{array}{l}\text { research } \\
\text { people care } \\
\text { new Care }\end{array}$ & $\begin{array}{c}\text { care } \\
\text { lịving }\end{array}$ \\
\hline Professionals & 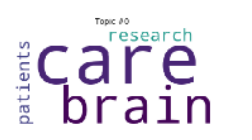 & $\begin{array}{l}\text { health } \\
\text { peopple } \\
\text { new care }\end{array}$ & $\underset{r i s k}{\text { brain }}$ & $\begin{array}{l}\text { people } \\
\text { research living } \\
\text { care }\end{array}$ \\
\hline E-Promoters & $\begin{array}{l}\text { resenco } \\
\text { carearch } \\
\text { end }\end{array}$ & $\begin{array}{c}\text { helphealth } \\
\text { people }\end{array}$ & 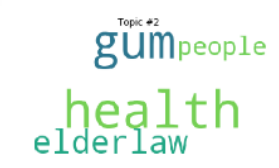 & $\begin{array}{l}\text { care }_{\text {friendly }} \\
\text { help }\end{array}$ \\
\hline $\begin{array}{l}\text { Empty and } \\
\text { Unknown }\end{array}$ & 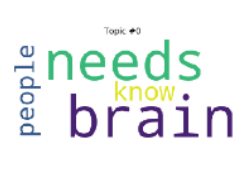 & $\begin{array}{l}\text { support } \\
\text { end carump } \\
\text { end care }\end{array}$ & $\begin{array}{l}\text { ctenew } \\
\text { health }\end{array}$ & $\begin{array}{l}\text { people } \\
\text { new } \\
\text { resealts } \\
\text { research }\end{array}$ \\
\hline $\begin{array}{l}\text { E-App and E- } \\
\text { Book }\end{array}$ & $\begin{array}{c}\text { people } \\
\text { memoir great } \\
\text { caregivers }\end{array}$ & $\begin{array}{l}\text { reseat } \\
\text { research } \\
\text { awareness } \\
\text { know study }\end{array}$ & $\begin{array}{l}\text { life epatients } \\
\text { people }\end{array}$ & $\begin{array}{l}\text { \$living } \\
\text { (1) care }\end{array}$ \\
\hline
\end{tabular}

Table 15: Topics of sub-categories of Individual Categories

\begin{tabular}{|c|c|c|c|c|}
\hline Users & Topic1 & Topic2 & Topic3 & Topic4 \\
\hline Advocators & $\begin{array}{c}\text { work } \\
\text { work } \\
\text { research } \\
\text { carestory }\end{array}$ & $\begin{array}{c}\text { tips love } \\
\text { Care }{ }_{\text {life }}^{\text {tore }} \text { e }\end{array}$ & $\begin{array}{c}\text { people } \\
\text { help caport } \\
\text { care }\end{array}$ & 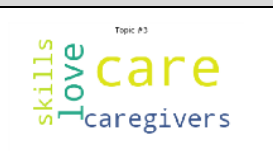 \\
\hline Carers & $\begin{array}{l}\underset{\text { ropik }}{\text { mom }} \\
\text { dad }_{\text {caregiving }} \\
\text { caregiver }\end{array}$ & $\begin{array}{c}\text { care } \\
\text { mum home } \\
\text { caregiver }\end{array}$ & $\begin{array}{c}{ }_{\text {paren }} \\
\text { caregiver } \\
\text { parents } \\
\text { dad } \stackrel{\overline{0}}{E}\end{array}$ & $\begin{array}{l}\text { caregiver } \\
\text { parentsmom }\end{array}$ \\
\hline Artists & $\begin{array}{l}\text { dad }_{1 \text { ike }}^{\text {rosico }} \\
\text { caregiver }\end{array}$ & $\begin{array}{l}\text { caregiver } \\
\text { supportived } \\
\text { need dad }\end{array}$ & $\begin{array}{l}\text { awareeness } \\
\text { greathelp } \\
\text { mother }\end{array}$ & 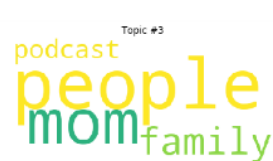 \\
\hline
\end{tabular}




\begin{tabular}{|c|c|c|c|c|}
\hline Authors & $\begin{array}{l}\text { help } \\
\text { endreaders }\end{array}$ & $\begin{array}{l}{ }^{\text {knowbrain }} \text { in } \\
\text { health }\end{array}$ & $\begin{array}{l}\text { book } \\
\text { memojem } \\
\text { video }\end{array}$ & $\begin{array}{l}\text { learn } \\
\text { hea }{ }_{\text {brainhealth }}\end{array}$ \\
\hline Markets & $\begin{array}{l}\text { resices } \\
\text { support }\end{array}$ & $\begin{array}{l}\text { researchers } \\
\text { welcome } \\
\text { healthcar } \\
\text { heare }\end{array}$ & 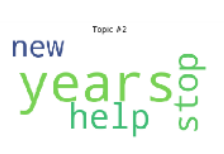 & $\begin{array}{l}\text { health } \\
\text { diagnosis } \\
\text { walkformemories }\end{array}$ \\
\hline
\end{tabular}

\section{Discussion}

The objective of this study was to establish the participants of dementia-related tweets, types of participant showing bot behavior and the features in dementia tweets' authors that contribute to bot-like behavior. We collected data with relevant hashtags and keywords. We then cleaned and pre-processed the data.

We applied inductive coding on cleaned data for categorizing tweets. We identified eight different user categories. All categories are bot score computed with BotOrNot? These categories were further sorted based on bot score, showing that the carers and books/apps categories have the highest mean bot scores. Also, in the carer category, many tweets were generated by software tools that show a high bot-like behavior. This led to further questions about what features are more influential in these categories and the contents of such tweets.

For profiles, we performed multivariate regression analysis with different groups of variables. The sample contained multiple independent variables. Seven different variables were tested to find the relationship of one or more variables in finding the bot score. From the analysis, it is found that geo_enabled, favorites count variables are strongly related with the final bot score in overall data, data in ranges $0-3$ and $1-5$, whereas the variable 'statuses count' had no impact on the final bot score in all samples. The summary of affected and unaffected variables is provided in Table 16.

Table 16: Summary

\begin{tabular}{llll}
\hline & $\mathrm{N}$ & Variables without effect & Variables with effect \\
\hline All users & 8400 & $\mathrm{X} 4, \mathrm{X} 6, \mathrm{X} 2$ & $\mathrm{X} 7, \mathrm{X} 5, \mathrm{X} 3, \mathrm{X} 1$ \\
Users Bot-score (3-5) & 1160 & $\mathrm{X} 1, \mathrm{X} 2, \mathrm{X} 3, \mathrm{X} 6$ & $\mathrm{X} 7, \mathrm{X} 4, \mathrm{X} 5$ \\
Users Bot-score (0-2.9) & 7231 & $\mathrm{X} 1, \mathrm{X} 2, \mathrm{X} 4, \mathrm{X} 6$ & $\mathrm{X} 7, \mathrm{X} 5, \mathrm{X} 3$ \\
\hline
\end{tabular}

There was another important finding related to the unusual pattern of bot scores in caregivers and books/apps. While these categories show a high average bot score, comparatively different bot-score distributions were found for these categories.

Content analysis was performed on the tweets in different categories. The frequency analysis of URLs in the tweets show that social media platforms are referred to frequently in the tweets, followed by news related websites such as BBC and The New York Times. Dementia-related websites and shopping apps have a lower usage frequency. Also, profiles with high bot scores used more popular URLs, irrespective of their tweeting frequency. This could be due to individuals advertising products. Websites related to dementia and care are referred to more in bot profiles compared to social media and ecommerce. Word level analysis showed that generally the word features of bot profiles are fewer in number compared to human profiles, apart from a few features. Also, the percentage of nouns used in bot profiles is much higher compared to human profiles.

This study shows certain categories such as carers and books/apps generate more bot-like behaviors. Also, features of user profiles such as geo_data, friends count, favorites count and verified variables are targeted by bots. Moreover, word-level analysis of tweets and topic modeling revealed features that can be helpful in assessing profile credibility. Thus, the analysis and integration of these features in a profile credibility framework can improve assessment. 


\section{Future Works}

This study focused on finding the relationship between independent variables in Twitter profiles with the accumulative bot score computed by BotOrNot? Initial results indicate the presence of this relationship. These results point to the need for the development of a Twitter credibility assessment model utilizing derived variables and existing independent variables. This work is an initial study for finding different features and can be extended by developing a credibility assessment framework based on identified influential features by correlating in well-balanced way.

\section{REFERENCES}

[1] S. Rieh, "Judgment of information quality and cognitive authority in the Web," J. Am. Soc. Inf. Sci. Technol., vol. 53, no. 2, pp. 145-161, 2002.

[2] S. Shyam Sundar, "The MAIN Model: A Heuristic Approach to Understanding Technology Effects on Credibility," Digit. media, youth, Credibil., pp. 73-100, 2008.

[3] C. N. Wathen and J. Burkell, "Believe it or not: Factors influencing credibility on the Web," J. Am. Soc. Inf. Sci. Technol., vol. 53, no. 2, pp. 134-144, 2002.

[4] M. D. Sumayyia, M. M. Al-Madaney, and F. H. Almousawi, "Health information on social media. Perceptions, attitudes, and practices of patients and their companions," Saudi Med. J., vol. 40, no. 12, pp. 1294-1298, 2019.

[5] Z. Zhang and W. Ahmed, "A comparison of information sharing behaviours across 379 health conditions on Twitter,” Int. J. Public Heal., vol. 64, no. 3, pp. 431-440, 2018.

[6] J. M. Robillard, T. W. Johnson, C. Hennessey, B. L. Beattie, and J. Illes, "Aging 2.0: Health Information about Dementia on Twitter," PLoS One, vol. 8, no. 7, pp. 1-5, 2013.

[7] M. Lawless, M. Augoustinos, and A. LeCouteur, "Dementia on Facebook: Requesting information and advice about dementia risk-prevention on social media," Discourse, Context Media, vol. 25, pp. 44-51, 2018.

[8] F. Morstatter, L. Wu, T. H. Nazer, K. M. Carley, and H. Liu, "A New Approach to Bot Detection:," IEEE/ACM Int. Conf. Adv. Soc. Networks Anal. Min., pp. 533-540, 2016.

[9] R. S. Geiger, "Bot-based collective blocklists in Twitter: the counterpublic moderation of harassment in a networked public space," Inf. Commun. Soc., vol. 19, no. 6, pp. 787-803, 2016.

[10]Z. Gilani, L. Wang, and M. Almeida, "Stweeler : A Framework for Twitter Bot Analysis," Iw3C2, no. 3, pp. 37-38, 2016.

[11]C. A. Davis, E. Ferrara, F. Menczer, and A. Flammini, "BotOrNot : A System to Evaluate Social Bots," pp. 4-5, 2016.

[12] Q. Liu, F. Yu, S. H. U. Wu, L. Wang, and C. Academy, "Mining Significant Microblogs for Misinformation Identification: An Attention-Based Approach," vol. 9, no. 5, 2018.

[13]C. Shao et al., "Anatomy of an online misinformation network," pp. 1-24, 2018.

[14] J. M. Burkhadrt, "SocialMedia Bots How they spread misinformation." americanlibrariesmagazine.org, 2018.

[15] J. Ratkiewicz, M. D. Conover, M. Meiss, B. Gonc, A. Flammini, and F. Menczer, "Detecting and Tracking Political Abuse in Social Media," pp. 297-304, 2010.

[16] A. Bessi and E. Ferrara, "Social bots distort the 2016 U.S. Presidential election online discussion," First Monday, vol. 21, no. 11, pp. 1-13, 2016.

[17] S. Choo and L. S. Wen, "Could Social Bots Pose a Threat to Public Health ?," Am. J. Public Health, vol. 108, no. 8, pp. 1005-1007, 2018.

[18]D. A. Broniatowski et al., "Weaponized Health Communication: Twitter Bots and Russian Trolls Amplify the Vaccine Debate," vol. 108, no. 10, pp. 1378-1384, 2018.

[19] C. Grimme, M. Preuss, L. Adam, and H. Trautmann, "Social Bots: Human-Like by Means of Human Control?,” Big Data, vol. 5, no. 4, pp. 279-293, 2017.

[20] A. Addawood, P. Balakumar, and J. Diesner, Categorization and Comparison of Influential Twitter Users and Sources Referenced in Tweets for Two Health-Related Topics, vol. 11420. Springer International Publishing, 2019.

[21] S. Park et al., "The Source and Credibility of Colorectal Cancer Information on Twitter," vol. 95, no. 7, pp. 1-7, 2016. 
[22] Y. Liu, "Mining Social Media to Understand Consumers ' Health Concerns and the Public 's Opinion on Controversial Health Topics," 2016.

[23] D. R. Thomas, "A General Inductive Approach for Analyzing Qualitative Evaluation Data," vol. 27, no. 2, pp. 237-246, 2006.

[24] J. Cohen, "\&dquo;two-legged," vol. XX, no. 1, pp. 37-46, 1960.

[25] J.-P. Allem, E. Ferrara, S. P. Uppu, T. B. Cruz, and J. B. Unger, "E-Cigarette Surveillance With Social Media Data: Social Bots, Emerging Topics, and Trends," JMIR Public Heal. Surveill., vol. 3, no. 4, p. e98, 2017.

[26] M. R. Morris, S. Counts, A. Roseway, A. Hoff, and J. Schwarz, "Tweeting is Believing ? Understanding Microblog Credibility Perceptions," 2012.

[27] C. Castillo, M. Mendoza, and B. Poblete, "Information credibility on Twitter," Proc. 20th Int. Conf. Companion World Wide Web, WWW 2011, pp. 675-684, 2011.

[28] G. R. S. Weir, "The Posit Text Profiling Toolset *," Proc. 12th Conf. Pan-Pacific Assoc. Appl. Linguist., 2007.

[29] G. R. S. Weir, E. Dos Santos, B. Cartwright, and R. Frank, "Positing the problem: Enhancing classification of extremist web content through textual analysis," 2016 IEEE Int. Conf. Cybercrime Comput. Forensic, ICCCF 2016, pp. 67-69, 2016.

[30] G. Weir, K. Owoeye, A. Oberacker, and H. Alshahrani, "Cloud-based textual analysis as a basis for document classification," Proc. - 2018 Int. Conf. High Perform. Comput. Simulation, HPCS 2018, pp. 629-633, 2018.

[31] L. M. Aiello et al., "Sensing Trending Topics in Twitter," IEEE Trans. Multimed., vol. 15, no. 6, pp. 1268-1282, 2013.

[32] J. Weng, E. Lim, J. Jiang, and H. Qi, “TwitterRank: Finding Topic-sensitive Influential Twitterers," in Third ACM International Conference on Web Search and Data Mining, 2010, pp. 261-270.

[33] K. R. Canini, B. Suh, and P. L. Pirolli, "Finding credible information sources in social networks based on content and social structure," Proc. - 2011 IEEE Int. Conf. Privacy, Secur. Risk Trust IEEE Int. Conf. Soc. Comput. PASSAT/SocialCom 2011, pp. 1-8, 2011. 